\title{
Gene Therapy: A Possible Alternative to CFTR Modulators?
}

\author{
J. Mercier ${ }^{1}$, M. Ruffin ${ }^{1}$, H. Corvol ${ }^{1,2}$ and L. Guillot ${ }^{1 *}$ \\ ${ }^{1}$ Sorbonne Université, Inserm, Centre de Recherche, Saint Antoine, F-75012, Paris, France, ${ }^{2}$ Pneumologie Pédiatrique, APHP, \\ Hôpital Trousseau, Paris, France
}

\section{OPEN ACCESS}

Edited by:

Miquéias Lopes-Pacheco, University of Lisbon, Portugal

Reviewed by: Giulio Cabrini, University of Ferrara, Italy Kamran Miah,

University of Oxford, United Kingdom

*Correspondence:

L. Guillot

loic.guillot@inserm.fr

Specialty section:

This article was submitted to Respiratory Pharmacology, a section of the journal

Frontiers in Pharmacology

Received: 31 December 2020 Accepted: 24 February 2021

Published: 21 April 2021

Citation:

Mercier J, Ruffin M, Corvol $H$ and Guillot L (2021) Gene Therapy: A Possible Alternative to CFTR Modulators?

Front. Pharmacol. 12:648203. doi: 10.3389/fphar.2021.648203
Cystic fibrosis (CF) is a rare genetic disease that affects several organs, but lung disease is the major cause of morbidity and mortality. The gene responsible for CF, the CFTR (Cystic Fibrosis Transmembrane Conductance Regulator) gene, has been discovered in 1989. Since then, gene therapy i.e., defective gene replacement by a functional one, remained the ultimate goal but unfortunately, it has not yet been achieved. However, patients care and symptomatic treatments considerably increased CF patients' life expectancy ranging from 5 years old in the 1960s to 40 today. In the last decade, research works on CFTR protein structure and activity led to the development of new drugs which, by readdressing CFTR to the plasma membrane (correctors) or by enhancing its transport activity (potentiators), allow, alone or in combination, an improvement of CF patients' lung function and quality of life. While expected, it is not yet known whether taking these drugs from an early age and for years will improve the quality of life of CF patients in the long term and further increase their life expectancy. Besides, these molecules are not available (specific variants of CFTR) or accessible (national health policies) for all patients and there is still no curative treatment. Another alternative that could benefit from new technologies, such as gene therapy, is therefore still attractive, although it is not yet offered to patients. Faced with the development of new CFTR correctors and potentiators, the question arises as to whether there is still a place for gene therapy and this is discussed in this perspective.

Keywords: cystic fibrosis, gene therapy, ivacaftor, lumacaftor, tezacaftor, personalized medicine

\section{INTRODUCTION}

Cystic fibrosis (CF) is a rare genetic disease caused by pathogenic variants in the CFTR (Cystic Fibrosis Transmembrane Conductance Regulator) gene, which encodes for a chloride channel expressed ubiquitously within epithelia. As a result, ionic and hydric imbalances across epithelia are observed in several organs, affecting their function. Specifically, manifestations can occur in the pancreas, liver, kidneys, and intestine, but lung disease is the main cause of morbidity and mortality of CF patients.

Since the CFTR gene discovery in 1989, more than 2000 variants of the CFTR gene have been identified. They were classified into six classes depending on their consequences on the CFTR protein. CF patients' life expectancy increased considerably between the 1960s and the beginning of the $21^{\text {st }}$ century mainly due to symptomatic treatment development and to patient management standardization. However, even if new promising drugs (called "CFTR modulators") directly targeting the CFTR protein are already available for some CF patients, there is still no curative treatment. Gene therapy, as defined by the delivery of a wild-type CFTR gene in cells, might be this curative treatment but is not yet available. 
TABLE 1 | CFTR modulators available for the treatment of CF patients. ppFEV1: percent-predicted Forced Expiratory Volume in 1 s; m.o.: months old; y.o.: years old. *only initial Phase III studies are cited. [detailed in (Lopes-Pacheco, 2019)].

\begin{tabular}{|c|c|c|c|c|}
\hline Molecules & First approval date & Eligibility age & Indication* & $\begin{array}{c}\text { Absolute } \\
\text { change in ppFEV1 }\end{array}$ \\
\hline \multirow[t]{2}{*}{ Ivacaftor } & 2012 & $\geq 6$ m.o. & G551D/other Ramsey et al. (2011) & $10.6 \%$ \\
\hline & & & Class III variants/Other Davies et al. (2013) & $12.5 \%$ \\
\hline Lumacaftor/ivacaftor & 2015 & $\geq 2$ y.o. & F508del/F508del Wainwright et al. (2015) & $2.8 \%$ \\
\hline \multirow[t]{2}{*}{ Tezacaftor/ivacaftor } & 2018 & $\geq 6$ y.o. & F508del/F508del Taylor-Cousar et al. (2017) & $4 \%$ \\
\hline & & & F508del/residual function variant in trans Rowe et al. (2017) & $6.8 \%$ \\
\hline \multirow[t]{2}{*}{ Elexacaftor/tezacaftor/ivacaftor } & 2019 & $\geq 12$ у.о. & F508del/minimal function variant in trans Middleton et al. (2019) & $13.8 \%$ \\
\hline & & & F508del/F508del Heijerman et al. (2019) & $10.4 \%$ \\
\hline
\end{tabular}

This perspective briefly describes the latest development of CFTR modulators and CFTR gene delivery strategies and discusses whether gene therapy is a still relevant alternative to be considered with respect to these promising molecules.

\section{CFTR Modulators}

In the last decade, new drugs called "CFTR modulators" addressing the direct consequences of CFTR variants on the CFTR protein have been identified thanks to high-throughput screening (extensively reviewed in (Lopes-Pacheco, 2019)). The two major types of CFTR modulators are correctors and potentiators. Correctors are intended to improve CFTR trafficking to the plasma membrane, while potentiators are designed to increase CFTR channel conductance. Thus, correctors and potentiators can only be effective on certain classes of CFTR variants i.e., those affecting CFTR protein trafficking (class II) and conductance (class III and IV). CFTR class I variants, that result in the absence of protein synthesis, and CFTR class V and VI variants, that lead to decreased CFTR protein quantity production, are excluded from modulator therapies. CFTR modulators approval represents a breakthrough in CF care because a significant improvement in patient's lung function (evaluated by measurements of FEV1 (forced expiratory volume in $1 \mathrm{~s}$ )) has been observed (Table 1).

Ivacaftor, the first potentiator designed to target the G551D gating variant (the most prevalent CFTR class III gating variant), showed in phase 3 clinical trial that patients gain more than $10 \%$ of FEV1 (Ramsey et al., 2011). Ivacaftor was then validated for other CFTR class III gating variants. A few years after, modulators targeting the most common CFTR variant called F508del (a class II variant) emerged. The combination of the corrector lumacaftor with the potentiator ivacaftor was approved for patient homozygotes for the F508del variant but showed limited FEV1 improvement. New correctors and combinations emerged further, which have more interesting effects on FEV1, allowing to address patients carrying only one F508del variant (Table 1). The latest combination (elexacaftor/tezacaftor/ivacaftor) showed indeed impressive results with a $14 \%$ increase in FEV1 (Heijerman et al., 2019; Middleton et al., 2019). Even if the level of increased lung function remains the principal measurement of treatment efficiency, these modulators have also been shown to be beneficial for other clinical parameters including increased body-mass index, improved life quality, and decreased exacerbations frequency.
Altogether, based on their age and genotype, around $80 \%$ of the patients reported in the Cystic Fibrosis Foundation Patient Registry are eligible for CFTR modulators (https://www.cff.org/Research/ Researcher-Resources/Patient-Registry/). According to this registry, $10 \%$ of the patients are still too young to be eligible for CFTR modulators; and the remaining $10 \%$ carry CFTR variants not currently known to be responsive to modulators or have unknown or incomplete genotypes. Among these patients, it has been estimated that $7 \%$ may require genetic-based therapy.

In this new promising era, some other concerns remain. For example, it should be noted that the hindsight on these treatments is limited, which makes it difficult to assess their long-term efficacy and tolerance. According to national health policies, the cost of these treatments might also be an obstacle to their access for all CF patients. Finally, as shown in a recent retrospective study, among $845 \mathrm{CF}$ patients who initiated lumacaftor/ivacaftor, $22.8 \%$ fully or temporarily discontinued their treatment mostly because of respiratory adverse events (Burgel et al., 2020). This could result in limiting the total number of patients who can benefit from these treatments.

The latest generation of modulator, the triple therapy, elexacaftor/ tezacaftor/ivacaftor, showed impressive results leading us to question in this perspective whether gene therapy is still attractive.

\section{GENE THERAPY: WHAT'S UP?}

Gene therapy consists of introducing a functional gene into host cells to replace a defective gene. Theoretically, this could be a perfect match for the needs of a monogenic disease as CF and could lead to a universal treatment for CF patients. Especially since Johnson and colleagues stated in 1992 that $6-10 \%$ of CFTRcorrected cells are sufficient to observe a therapeutic effect in vitro (Johnson et al., 1992), we can speculate that correction of all CF airway cells may not be mandatory to observe the same effect in vivo. However, the race for CF gene therapy turned out to be more challenging than expected so far.

\section{Lungs: Barriers to Delivery}

The lung represents an organ of choice for the delivery of organspecific treatments due to its ease of access. Therefore, aerosol administration has been widely used in previous clinical trials of pulmonary gene therapy as reviewed by Resnier et al. (Resnier et al., 2016). However, the major difficulty encountered in these 


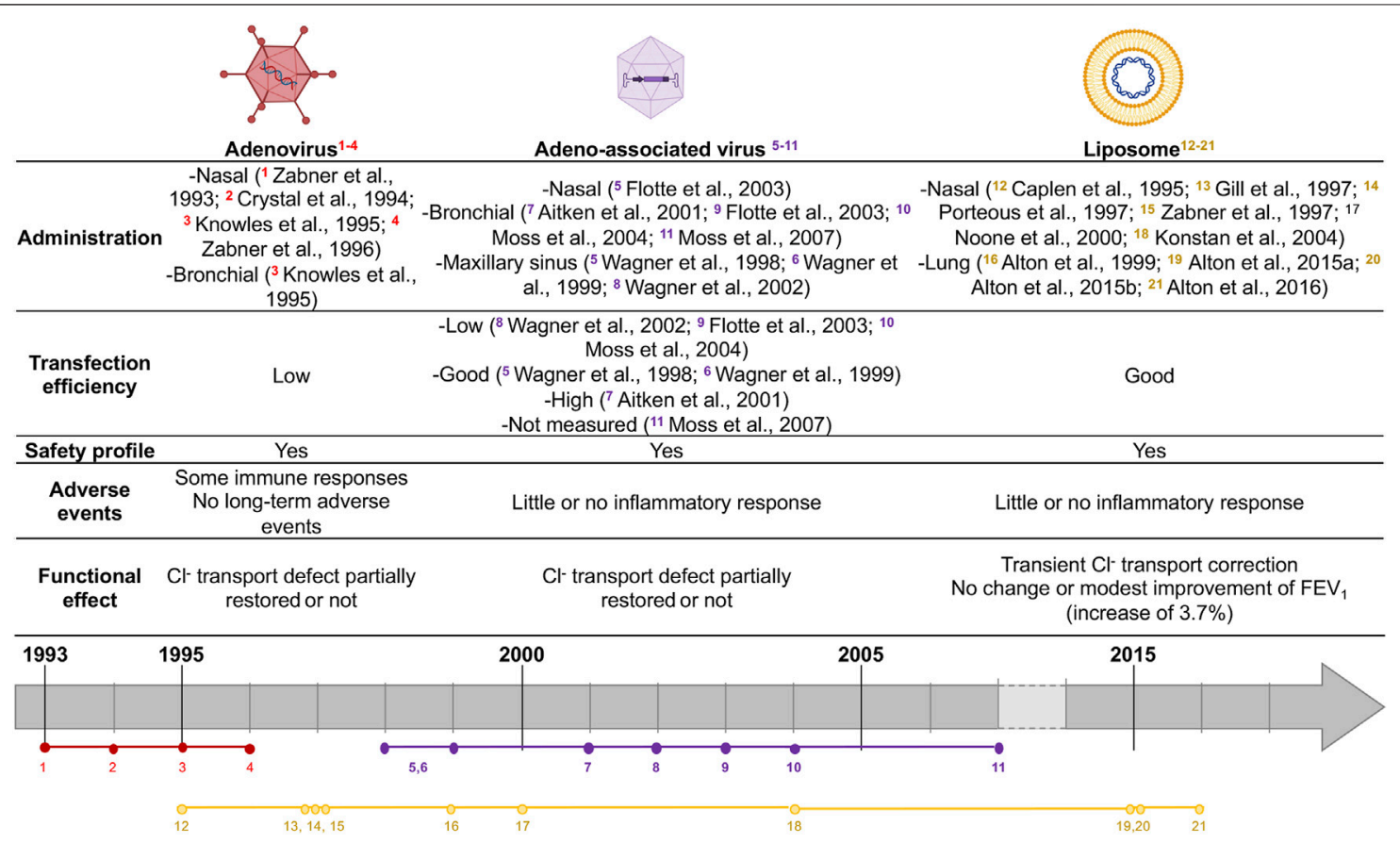

FIGURE 1 | Summary of CF gene therapy clinical trials. Colors represent vector agent used (red: Ad, purple: AAV, yellow: liposome). Vectors agent made with biorender: https://biorender.com.

trials is the delivery of the gene into airway epithelial cells. Indeed, mucus, mucociliary clearance, and lung immune responses complicate the entry of the gene transfer agent into target cells, and the few that succeed encounters a new obstacle: the nuclear membrane (Yonemitsu et al., 2000; Stern et al., 2003; Schuster et al., 2014; Xia et al., 2014). Moreover, since the airway epithelium renews itself gradually, another challenge is to target progenitor cells to obtain a permanent treatment and avoid repeated required deliveries (Gill and Hyde, 2014).

\section{CFTR Gene Delivery Methods: Advantages and Limitations}

Only 1 year after the CFTR gene discovery in 1989 (Kerem et al., 1989; Riordan et al., 1989; Rommens et al., 1989), two groups independently showed that it was possible to produce a functional CFTR protein by using a viral vector to introduce the full-length CFTR gene in vitro (Drumm et al., 1990; Rich et al., 1990). This proof of concept paved the way for the beginning of CF gene therapy clinical trials (Figure 1). To efficiently introduce a normal CFTR gene into cells, various delivery strategies have been developed for three decades, including viral and non-viral vector systems, and are briefly presented after (recently reviewed in detail by (Cooney et al., 2018; Schneider-Futschik, 2019; Yan et al., 2019)).

\section{Viral Vectors}

Viruses have a high natural capacity to infect host cells and were modified by scientists to decrease their pathogenicity. Thus, recombinant vectors expressing a foreign antigenic protein or a functional protein were created and used for vaccines or gene therapy, respectively.

\section{Recombinant Adenovirus Vector}

Recombinant Adenovirus-based vectors (rAd-vector) were the first viral vectors used in CF gene therapy clinical trials. They are non-enveloped viruses with a linear and double-stranded DNA genome. Commonly, two serotypes are observed beyond Ad type 2 (Ad2) or type 5 (Ad5) which allow host-cell binding. In vivo studies showed that Ad-vectors were transduced in all airway epithelial cell types (Mastrangeli et al., 1993) and also in submucosal glands (Pilewski et al., 1995). The first use of Advectors with CFTR gene in CF gene therapy clinical trial showed that their delivery was safe, with little or no immune response and a partial correction of $\mathrm{Cl}^{-}$transport defect (Zabner et al., 1993; Zabner et al., 1996). Crystal et al. showed that rAd-CFTR protein was expressed in the airway epithelium 4 days after intrabronchial administration. They tested doses up to $2 \times 10^{9} \mathrm{pfu}$, which led to short-term adverse events such as transient systemic inflammation (Crystal et al., 1994). No other adverse event was reported after a 6-months follow-up. Another trial showed no evidence of CFTR functional defect correction, probably due to inflammatory responses (Knowles et al., 1995). Thus, rAd-vectors are capable of transducing and occasionally correcting $\mathrm{Cl}^{-}$ transport defect in CF human airway epithelial cells. Yet, some inflammatory responses were observed. Besides, rAd-vector DNA does not integrate the host cell genome but rather persists within the cells as episomal DNA (Athanasopoulos et al., 2017). Finally, rAd-vector DNA is not replicated upon cell divisions, requiring multiple deliveries for patients. 


\section{Recombinant Adeno-Associated Virus Vector}

Recombinant adeno-associated virus vectors (rAAV) are characterized by their ability to transduce both dividing and quiescent cells and by their high transduction efficiency in primary human airway (Yan et al., 2013). Those vectors are less immunogenic than Ad-vectors and were the most used vectors in CF gene therapy clinical trials, showing a strong safety profile record but failed in improving the lung function (Wagner et al., 1999; Wagner et al., 1998; Aitken et al., 2001; Wagner et al., 2002; Flotte et al., 2003; Moss et al., 2007) (Figure 1).

A limitation of rAAV vector is its packaging capacity limited to $4.8 \mathrm{~kb}$ (Blacklow et al., 1988; Wu et al., 2010). The small size of this vector may give it an advantage to enter cells more easily but considering that the size of the CFTR gene is $4.6 \mathrm{~kb}$, there is almost no space left for regulatory sequences allowing CFTR gene expression enhancement. As reviewed by Cooney and coll., the shortening of the CFTR gene and other cassette sequences led to a generation of modified AAV vectors that expressed functional CFTR.

Moreover, rAAVs vectors genome integrates into the human genome (Kotin et al., 1991; Samulski et al., 1991; Kotin et al., 1992; Rivadeneira et al., 1998; Ding et al., 2003; Janovitz et al., 2014) and can also persist as episomal DNA in post-mitotic tissues when the replication protein rep is absent (Athanasopoulos et al, 2017). Besides, rAAV-mediated transduction has been proved to induce a long-lasting gene expression up to several months in pigs (Steines et al., 2016) and better rAAV vectors allowing an increased packaging capacity and higher tropism for airway epithelial cells are developed (Yan et al., 2019).

\section{Helper-Dependent Adenovirus Vector}

Helper-dependent adenovirus (Hd-Ad) vectors, which have had all viral genes deleted, were developed to circumvent inflammatory properties of rAd-vectors (Parks et al., 1996). With a $36 \mathrm{~kb}$ packaging capacity (Cots et al., 2013), they circumvent little packaging capacities of rAAV-vectors. Multiple serotypes of Hd-Ad vectors have been tested but serotype 5 showed effective transduction in vivo in airways basal cells in mouse and pig models and, in vitro, in primary human airway epithelial cell cultures (Cao et al., 2018; Palmer et al., 2020).

\section{Lentivirus}

Finally, the last type of viral vector used for CF gene therapy studies is lentiviral vector, which could allow a genomic integration and provide a long-term expression (Naldini et al., 1996) without repeated administrations. Even if LV vectors seem less likely to be destroyed by immune system than rAAVs, because of no-prexisting immunity (neutralizing antibodies), they activate the immune system as the other viral vectors (Nayak and Herzog, 2010). LV-mediated transgene integration site into the host genome can be multiple, extremely variable and potentially leading to proto-oncogenes activation. This property led to the interruption of a clinical trial in severe combined immunodeficiency patients (Hacein-Bey-Abina et al., 2003a; Hacein-Bey-Abina et al., 2003b; Fischer et al., 2004; Fischer and Cavazzana-Calvo, 2005; Hacein-Bey-Abina et al., 2008). In order to circumvent this, LV vectors design was then improved with self-inactivating (SIN) of long terminal repeats (LTRs), reducing the genotoxic risk of these strong enhancer-promoter sequences (Modlich and Baum, 2009; Milone and O'Doherty, 2018). Thus, lentiviruses still seem to be interesting vectors for $\mathrm{CF}$ gene therapy as some lentiviral vector pseudotypes demonstrated high vector production and apical tropism to airway epithelium in vitro and in vivo (Sinn et al., 2005; McKay et al., 2006). Plus, repeated administration was possible without blocking antibody immune responses (Sinn et al., 2008; Griesenbach et al., 2012) and LV efficiency was demonstrated in several animal models including mice, ferret and pigs (Oakland et al., 2013; Yan et al., 2015; Cooney et al., 2016). Recently, a study with a promising lentiviral vector developed by the United Kingdom Cystic Fibrosis Gene Therapy consortium showed a 14\% airway cells transduction efficiency in vitro, low toxicity and an integration site profile supporting a future first-in-man trial (Alton et al., 2017).

Nevertheless, viral vectors use can be limited by several factors. Firstly, neutralizing antibodies to Ad or AAV, due to the immune response to previous natural infection, are frequently found in patients, rendering them ineligible for this kind of treatments (Erles et al., 1999). Secondly, viral vectors internalization into host cells requires receptors such as $\alpha_{\mathrm{V}}$ integrins (Wickham et al., 1993), Coxsackie-Adenovirus Receptor (Bergelson et al., 1997), heparan sulfate glycosaminoglycans (Dechecchi et al., 2001) or fibroblast growth factor receptors (Duan et al., 1998) that are expressed on the basolateral membrane of bronchial epithelial cells, thus explaining the lack of transduction efficiency (Duan et al., 1998; Pickles et al., 1998; Marquez Loza et al., 2019). Pseudotyping viral vectors with proteins able to interact with apical membrane receptors of airway epithelial cells is thus required to enhance delivery efficiency.

\section{Non-Viral Vectors}

Non-viral vectors allow genomic material delivery into cells by direct administration as naked DNA or associated with different compounds. Those vectors have theoretically no size restrictions and have mainly three possible configurations: lipid-based, peptide-based or polymer-based delivery. They can carry plasmid or linear DNA as well as RNA molecules. A non-viral strategy for CFTR delivery was considered as an alternative to viral vectors. Indeed, several studies showed that cationic lipids were safe delivery vehicles for gene transfer (Kollen et al., 1996; Fasbender et al., 1998; McDonald et al., 1998), their main issue remaining the limited transgene delivery into the nucleus (Brisson et al., 1999). However, as recently reviewed (Cooney et al., 2018), several clinical trials using cationic lipids showed transient expression of vector related-CFTR for few days and partial restoration of nasal potential differences in CF patients without significant clinical effect on lung function (Caplen et al., 1995; Gill et al., 1997; Porteous et al., 1997; Zabner et al., 1997; Alton et al., 1999; Noone et al., 2000; Ruiz et al., 2001; Konstan et al., 2004). In 2015, Alton and colleagues reported an increase in FEV1 of 3.7\% (0.07-7.25\%) after using pGM169/GL67A cationic lipid (Alton et al., 2015b) in patients who received nebulized 
vector at 28 days intervals for 12 months (Alton et al., 2015a). However, as FEV1 improvements observed were only comparable to those obtained with some CFTR modulators, trial did not result in the current clinical application for CF patients. Alton et al. now focused on alternative lentiviral vectors candidates, such as the lentiviral vector based on simian immunodeficiency virus (SIV) pseudotyped with Sendaï virus envelope proteins Fusion (F) and Hemagglutinin-Neuraminidase (HN) (rSIV.F/HN), which retains 90-100\% transduction efficiency and leads to a functional CFTR expression in preclinical models (Alton et al., 2016; Alton et al., 2017).

\section{GENE THERAPY STILL TO CONSIDER?}

To date, CF gene therapy clinical trials have not been conclusive, with a weak effect observed on CF patients' lung function, associated with important immune responses, which may render the treatment ineffective. Moreover, as mentioned previously, the recent developments of effective drugs such as the triple combination elexacaftor/tezacaftor/ivacaftor, which greatly improves patients' lung function and quality of life, has given rise to the idea that "cystic fibrosis is almost cured". Thus, it is therefore legitimate to wonder to what extent gene therapy still has a place in the treatment of CF. However, it should be remembered that the drugs currently on the market still leave aside at least $10 \%$ of CF patients without curative treatment, as highlighted by the Cystic Fibrosis Foundation patient registry. In addition, current CFTR modulators are not well tolerated by all eligible patients and real-life studies show that numerous patients stop their treatment. Besides, we do not have enough hindsight to predict effectiveness of these promising drugs in the long term.

Over the last 20 years, gene therapy has shown successful transient or permanent results for several diseases such as $\mathrm{X}$-linked severe combined immune deficiency (CavazzanaCalvo et al., 2000), adenosine deaminase deficiency (Cicalese et al., 2016), Leber congenital amaurosis (Cideciyan et al., 2013), hemophilia (Nathwani et al., 2011), severe betaThalassemia (Cavazzana-Calvo et al., 2010; Persons, 2010), but also Parkinson's disease (Palfi et al., 2014) or leukemia, with 27 children who experienced complete remission after treatment (Maude et al., 2014). In 2012, the first viral gene-therapy treatment was approved in Europe for treatment of lipoprotein lipase deficiency (Yla-Herttuala, 2012) and showed good results

\section{REFERENCES}

Aitken, M. L., Moss, R. B., Waltz, D. A., Dovey, M. E., Tonelli, M. R., McNamara, S. C., et al. (2001). A phase I study of aerosolized administration of tgAAVCF to cystic fibrosis subjects with mild lung disease. Hum. Gene Ther. 12 (15), 1907-1916. doi:10.1089/104303401753153956

Alton, E., Armstrong, D. K., Ashby, D., Bayfield, K. J., Bilton, D., Bloomfield, E. V., et al. (2016). A randomised, double-blind, placebo-controlled trial of repeated nebulisation of non-viral cystic fibrosis transmembrane conductance regulator (CFTR) gene therapy in patients with cystic fibrosis (Southampton (UK):NIHR Journals Library. doi:10.3310/eme03050 even years later (Gaudet et al., 2016). Recently, gene therapy also showed promising results for Leber hereditary optic neuropathy by improving bilateral vision in patients over 96 weeks of followup after a unilateral intravitreal injection (Yu-Wai-Man et al., 2020). These successful trials were carried out on easily accessible hematopoietic stem cells or by direct vectors injections into specific tissues, which may explain previous trials failure in $\mathrm{CF}$ compared to other diseases.

In addition to wild-type CFTR gene delivery strategy, CFTR gene editing with CRISPR/Cas9 technology emerged as a promising therapeutic option for CF patients (Hodges and Conlon, 2019). New strategies are also currently tested in ongoing trials, such as RESTORE-CF phase I/II clinical trial (http:// ClinicalTrials.gov Identifier: NCT03375047), which evaluates safety and tolerability of MRT5005, an RNA-based therapy. RNA-based therapy has the advantage of not disturbing the genome, however would require repeated doses. Another promising strategy is to combine gene therapy with pluripotent stem cells (iPSCs). As a proof of concept, Hawkins et al. succeeded to derive airway basal cells from human iPSCs, to perform an engraftment and to allow epithelial regeneration in vivo using a tracheal xenograft model in immune-compromized mice, with similar structure and composition than in vivo airways (Hawkins et al., 2020). The long-term goal is to obtain a de novo generation of the full diversity of lung lineages and transplantable 3D lung tissues, that could be corrected by gene therapy and transferred into CF patients (Kotton, 2012).

In conclusion, CF gene therapy still has a bright future ahead. The main current challenge is to circumvent technical problems of transduction encountered in the lung. If this happens one day, not only will CF be truly cured, but the gene therapy might also be applied to other lung genetic diseases.

\section{AUTHOR CONTRIBUTIONS}

JM, MR, HC, and LG wrote the manuscript.

\section{ACKNOWLEDGMENTS}

MR received a postdoctoral fellowship from the French cystic fibrosis non-profit organization Vaincre la mucoviscidose (RF20190502451).

Alton, E., Stern, M., Farley, R., Jaffe, A., Chadwick, S., Phillips, J., et al. (1999). Cationic lipid-mediated CFTR gene transfer to the lungs and nose of patients with cystic fibrosis: a double-blind placebo-controlled trial. The Lancet 353 (9157), 947-954. doi:10.1016/s0140-6736(98) 06532-5

Alton, E. W. F. W., Armstrong, D. K., Ashby, D., Bayfield, K. J., Bilton, D., Bloomfield, E. V., et al. (2015a). Repeated nebulisation of non-viral CFTR gene therapy in patients with cystic fibrosis: a randomised, double-blind, placebocontrolled, phase 2b trial. Lancet Respir. Med. 3 (9), 684-691. doi:10.1016/ S2213-2600(15)00245-3

Alton, E. W. F. W., Beekman, J. M., Boyd, A. C., Brand, J., Carlon, M. S., Connolly, M. M., et al. (2017). Preparation for a first-in-man lentivirus trial in patients 
with cystic fibrosis. Thorax 72 (2), 137-147. doi:10.1136/thoraxjnl-2016208406

Alton, E. W. F. W., Boyd, A. C., Porteous, D. J., Davies, G., Davies, J. C., Griesenbach, U., et al. (2015b). A phase I/IIa safety and efficacy study of nebulized liposome-mediated gene therapy for cystic fibrosis supports a multidose trial. Am. J. Respir. Crit. Care Med. 192 (11), 1389-1392. doi:10. 1164/rccm.201506-1193LE

Athanasopoulos, T., Munye, M. M., and Yáñez-Muñoz, R. J. (2017). Nonintegrating gene therapy vectors. Hematology/Oncology Clin. North America 31 (5), 753-770. doi:10.1016/j.hoc.2017.06.007

Bergelson, J. M., Cunningham, J. A., Droguett, G., Kurt-Jones, E. A., Krithivas, A., Hong, J. S., et al. (1997). Isolation of a common receptor for Coxsackie B viruses and adenoviruses 2 and 5. Science 275 (5304), 1320-1323. doi:10.1126/science. 275.5304.1320

Blacklow, S. C., Raines, R. T., Lim, W. A., Zamore, P. D., and Knowles, J. R. (1988). Triosephosphate isomerase catalysis is diffusion controlled. Biochemistry 27 (4), 1158-1165. doi:10.1021/bi00404a013

Brisson, M., Tseng, W.-C., Almonte, C., Watkins, S., and Huang, L. (1999). Subcellular trafficking of the cytoplasmic expression system. Hum. Gene Ther. 10 (16), 2601-2613. doi:10.1089/10430349950016645

Burgel, P. R., Munck, A., Durieu, I., Chiron, R., Mely, L., Prevotat, A., et al. (2020). Real-life safety and effectiveness of lumacaftor-ivacaftor in patients with cystic fibrosis. Am. J. Respir. Crit. Care Med. 201 (2), 188-197. doi:10.1164/rccm. 201906-1227OC

Cao, H., Ouyang, H., Grasemann, H., Bartlett, C., Du, K., Duan, R., et al. (2018). Transducing airway basal cells with a helper-dependent adenoviral vector for lung gene therapy. Hum. Gene Ther. 29 (6), 643-652. doi:10.1089/hum. 2017.201

Caplen, N. J., Alton, E. W. F. W., Mddleton, P. G., Dorin, J. R., Stevenson, B. J., Gao, X., et al. (1995). Liposome-mediated CFTR gene transfer to the nasal epithelium of patients with cystic fibrosis. Nat. Med. 1 (1), 39-46. doi:10.1038/nm0195-39

Cavazzana-Calvo, M., Hacein-Bey, S., de Saint Basile, G., Gross, F., Yvon, E., Nusbaum, P., et al. (2000). Gene therapy of human severe combined immunodeficiency (SCID)-X1 disease. Science 288 (5466), 669-672. doi:10. 1126/science.288.5466.669

Cavazzana-Calvo, M., Payen, E., Negre, O., Wang, G., Hehir, K., Fusil, F., et al. (2010). Transfusion independence and HMGA2 activation after gene therapy of human $\beta$-thalassaemia. Nature 467 (7313), 318-322. doi:10.1038/nature09328

Cicalese, M. P., Ferrua, F., Castagnaro, L., Pajno, R., Barzaghi, F., Giannelli, S., et al. (2016). Update on the safety and efficacy of retroviral gene therapy for immunodeficiency due to adenosine deaminase deficiency. Blood 128 (1), 45-54. doi:10.1182/blood-2016-01-688226

Cideciyan, A. V., Jacobson, S. G., Beltran, W. A., Sumaroka, A., Swider, M., Iwabe, S., et al. (2013). Human retinal gene therapy for Leber congenital amaurosis shows advancing retinal degeneration despite enduring visual improvement. Proc. Natl. Acad. Sci. U. S. A. 110 (6), E517-E525. doi:10.1073/pnas.1218933110

Cooney, A. L., Abou Alaiwa, M. H., Shah, V. S., Bouzek, D. C., Stroik, M. R., Powers, L. S., et al. (2016). Lentiviral-mediated phenotypic correction of cystic fibrosis pigs. JCI Insight 1 (14), e88730. doi:10.1172/jci.insight.88730

Cooney, A., McCray, P., Jr., and Sinn, P. (2018). Cystic fibrosis gene therapy: looking back, looking forward. Genes 9 (11), 538. doi:10.3390/genes 9110538

Cots, D., Bosch, A., and Chillón, M. (2013). Helper dependent adenovirus vectors: progress and future prospects. Cgt 13 (5), 370-381. doi:10.2174/ 156652321305131212125338

Crystal, R. G., McElvaney, N. G., Rosenfeld, M. A., Chu, C.-S., Mastrangeli, A., Hay, J. G., et al. (1994). Administration of an adenovirus containing the human CFTR cDNA to the respiratory tract of individuals with cystic fibrosis. Nat. Genet. 8 (1), 42-51. doi:10.1038/ng0994-42

Davies, J. C., Wainwright, C. E., Canny, G. J., Chilvers, M. A., Howenstine, M. S., Munck, A., et al. (2013). Efficacy and safety of ivacaftor in patients aged 6 to 11 years with cystic fibrosis with aG551D Mutation. Am. J. Respir. Crit. Care Med. 187 (11), 1219-1225. doi:10.1164/rccm.201301-0153OC

Dechecchi, M. C., Melotti, P., Bonizzato, A., Santacatterina, M., Chilosi, M., and Cabrini, G. (2001). Heparan sulfate glycosaminoglycans are receptors sufficient to mediate the initial binding of adenovirus types 2 and 5. J. Virol. 75 (18), 8772-8780. doi:10.1128/jvi.75.18.8772-8780.2001

Ding, W., Yan, Z., Zak, R., Saavedra, M., Rodman, D. M., and Engelhardt, J. F. (2003). Second-strand genome conversion of adeno-associated virus type 2
(AAV-2) and AAV-5 is not rate limiting following apical infection of polarized human airway epithelia. J Virol. 77 (13), 7361-7366. doi:10.1128/jvi.77.13.73617366.2003

Drumm, M. L., Pope, H. A., Cliff, W. H., Rommens, J. M., Marvin, S. A., Tsui, L.-C., et al. (1990). Correction of the cystic fibrosis defect in vitro by retrovirusmediated gene transfer. Cell 62 (6), 1227-1233. doi:10.1016/0092-8674(90) 90398-x

Duan, D., Yue, Y., Yan, Z., McCray, P. B., Jr., and Engelhardt, J. F. (1998). Polarity influences the efficiency of recombinant adenoassociated virus infection in differentiated airway epithelia. Hum. Gene Ther. 9 (18), 2761-2776. doi:10. 1089/hum.1998.9.18-2761

Erles, K., Sebokova, P., and Schlehofer, J. R. (1999). Update on the prevalence of serum antibodies (IgG and $\operatorname{IgM}$ ) to adeno-associated virus (AAV). J. Med. Virol. 59 (3), 406-411. doi:10.1002/(sici)1096-9071(199911)59:3<406:aidjimv22>3.0.co;2-n

Fasbender, A., Lee, J. H., Walters, R. W., Moninger, T. O., Zabner, J., and Welsh, M. J. (1998). Incorporation of adenovirus in calcium phosphate precipitates enhances gene transfer to airway epithelia in vitro and in vivo. J. Clin. Invest. 102 (1), 184-193. doi:10.1172/JCI2732

Fischer, A., and Cavazzana-Calvo, M. (2005). Integration of retroviruses: a fine balance between efficiency and danger. Plos Med. 2 (1), e10. doi:10.1371/ journal.pmed.0020010

Fischer, A., Abina, S. H., Thrasher, A., von Kalle, C., and Cavazzana-Calvo, M. (2004). LMO2 and gene therapy for severe combined immunodeficiency. N. Engl. J. Med. 350 (24), 2526-2527. doi:10.1056/ NEJM200406103502422

Flotte, T. R., Zeitlin, P. L., Reynolds, T. C., Heald, A. E., Pedersen, P., Beck, S., et al. (2003). Phase I trial of intranasal and endobronchial administration of a recombinant adeno-associated virus serotype 2 (rAAV2)-CFTR vector in adult cystic fibrosis patients: a two-part clinical study. Hum. Gene Ther. 14 (11), 1079-1088. doi:10.1089/104303403322124792

Gaudet, D., Stroes, E. S., Méthot, J., Brisson, D., Tremblay, K., Bernelot Moens, S. J., et al. (2016). Long-term retrospective analysis of gene therapy with alipogene tiparvovec and its effect on lipoprotein lipase deficiency-induced pancreatitis. Hum. Gene Ther. 27 (11), 916-925. doi:10.1089/hum.2015.158

Gill, D. R., and Hyde, S. C. (2014). Delivery of genes into the CF airway. Thorax 69 (10), 962-964. doi:10.1136/thoraxjnl-2014-205835

Gill, D., Southern, K., Mofford, K., Seddon, T., Huang, L., Sorgi, F., et al. (1997). A placebo-controlled study of liposome-mediated gene transfer to the nasal epithelium of patients with cystic fibrosis. Gene Ther. 4 (3), 199-209. doi:10. 1038/sj.gt.3300391

Griesenbach, U., Inoue, M., Meng, C., Farley, R., Chan, M., Newman, N. K., et al. (2012). Assessment of F/HN-pseudotyped lentivirus as a clinically relevant vector for lung gene therapy. Am. J. Respir. Crit. Care Med. 186 (9), 846-856. doi:10.1164/rccm.201206-1056OC

Hacein-Bey-Abina, S., Garrigue, A., Wang, G. P., Soulier, J., Lim, A., Morillon, E., et al. (2008). Insertional oncogenesis in 4 patients after retrovirus-mediated gene therapy of SCID-X1. J. Clin. Invest. 118 (9), 3132-3142. doi:10.1172/ JCI35700

Hacein-Bey-Abina, S., von Kalle, C., Schmidt, M., Le Deist, F., Wulffraat, N., McIntyre, E., et al. (2003a). A serious adverse event after successful gene therapy for X-linked severe combined immunodeficiency. N. Engl. J. Med. 348 (3), 255-256. doi:10.1056/NEJM200301163480314

Hacein-Bey-Abina, S., Von Kalle, C., Schmidt, M., McCormack, M. P., Wulffraat, N., Leboulch, P., et al. (2003b). LMO2-associated clonal T cell proliferation in two patients after gene therapy for SCID-X1. Science 302 (5644), 415-419. doi:10.1126/science.1088547

Hawkins, F. J., Suzuki, S., Beermann, M. L., Barillà, C., Wang, R., Villacorta-Martin, C., et al. (2021). Derivation of airway basal stem cells from human pluripotent stem cells. Cell Stem Cell 28, 79. doi:10.1016/j.stem.2020.09.017

Heijerman, H. G. M., McKone, E. F., Downey, D. G., Van Braeckel, E., Rowe, S. M., Tullis, E., et al. (2019). Efficacy and safety of the elexacaftor plus tezacaftor plus ivacaftor combination regimen in people with cystic fibrosis homozygous for the F508del mutation: a double-blind, randomised, phase 3 trial. The Lancet 394 (10212), 1940-1948. doi:10.1016/S0140-6736(19)32597-8

Hodges, C. A., and Conlon, R. A. (2019). Delivering on the promise of gene editing for cystic fibrosis. Genes Dis. 6 (2), 97-108. doi:10.1016/j.gendis.2018. 11.005 
Janovitz, T., Oliveira, T., Sadelain, M., Falck-Pedersen, E., and Imperiale, M. J. (2014). Highly divergent integration profile of adeno-associated virus serotype 5 revealed by high-throughput sequencing. J. Virol. 88 (5), 2481-2488. doi:10. 1128/JVI.03419-13

Johnson, L. G., Olsen, J. C., Sarkadi, B., Moore, K. L., Swanstrom, R., and Boucher, R. C. (1992). Efficiency of gene transfer for restoration of normal airway epithelial function in cystic fibrosis. Nat. Genet. 2 (1), 21-25. doi:10.1038/ ng0992-21

Kerem, B., Rommens, J., Buchanan, J., Markiewicz, D., Cox, T., Chakravarti, A., et al. (1989). Identification of the cystic fibrosis gene: genetic analysis. Science 245 (4922), 1073-1080. doi:10.1126/science.2570460

Knowles, M. R., Hohneker, K. W., Zhou, Z., Olsen, J. C., Noah, T. L., Hu, P.-C., et al. (1995). A controlled study of adenoviral-vector-mediated gene transfer in the nasal epithelium of patients with cystic fibrosis. N. Engl. J. Med. 333 (13), 823-831. doi:10.1056/NEJM199509283331302

Kollen, W. J. W., Midoux, P., Erbacher, P., Yip, A., Roche, A. C., Monsigny, M., et al. (1996). Gluconoylated and glycosylated polylysines as vectors for gene transfer into cystic fibrosis airway epithelial cells. Hum. Gene Ther. 7 (13), 1577-1586. doi:10.1089/hum.1996.7.13-1577

Konstan, M. W., Davis, P. B., Wagener, J. S., Hilliard, K. A., Stern, R. C., Milgram, L. J. H., et al. (2004). Compacted DNA nanoparticles administered to the nasal mucosa of cystic fibrosis subjects are safe and demonstrate partial to complete cystic fibrosis transmembrane regulator reconstitution. Hum. Gene Ther. 15 (12), 1255-1269. doi:10.1089/hum.2004.15.1255

Kotin, R. M., Linden, R. M., and Berns, K. I. (1992). Characterization of a preferred site on human chromosome $19 \mathrm{q}$ for integration of adeno-associated virus DNA by non-homologous recombination. EMBO J. 11 (13), 5071-5078. doi:10.1002/ j.1460-2075.1992.tb05614.x

Kotin, R. M., Menninger, J. C., Ward, D. C., and Berns, K. I. (1991). Mapping and direct visualization of a region-specific viral DNA integration site on chromosome 19q13-qter. Genomics 10 (3), 831-834. doi:10.1016/08887543(91)90470-y

Kotton, D. N. (2012). Next-generation regeneration: the hope and hype of lung stem cell research. Am. J. Res. Crit. Care Med. 185, 1255-1260. doi:10.1164/ rccm.201202-0228PP

Lopes-Pacheco, M. (2019). CFTR modulators: the changing face of cystic fibrosis in the era of precision medicine. Front. Pharmacol. 10, 1662. doi:10.3389/fphar. 2019.01662

Marquez Loza, L., Yuen, E., and McCray, P., Jr. (2019). Lentiviral vectors for the treatment and prevention of cystic fibrosis lung disease. Genes 10 (3), 218. doi:10.3390/genes10030218

Mastrangeli, A., Danel, C., Rosenfeld, M. A., Stratford-Perricaudet, L., Perricaudet, M., Pavirani, A., et al. (1993). Diversity of airway epithelial cell targets for in vivo recombinant adenovirus-mediated gene transfer. J. Clin. Invest. 91 (1), 225-234. doi:10.1172/JCI116175

Maude, S. L., Frey, N., Shaw, P. A., Aplenc, R., Barrett, D. M., Bunin, N. J., et al. (2014). Chimeric antigen receptor T cells for sustained remissions in leukemia. N. Engl. J. Med. 371 (16), 1507-1517. doi:10.1056/NEJMoa1407222

McDonald, R. J., Liggitt, H. D., Roche, L., Nguyen, H. T., Pearlman, R., Raabe, O. G., et al. (1998). Aerosol delivery of lipid:DNA complexes to lungs of rhesus monkeys. Pharm. Res. 15 (5), 671-679. doi:10.1023/a: 1011902532163

McKay, T., Patel, M., Pickles, R. J., Johnson, L. G., and Olsen, J. C. (2006). Influenza $\mathrm{M} 2$ envelope protein augments avian influenza hemagglutinin pseudotyping of lentiviral vectors. Gene Ther. 13 (8), 715-724. doi:10.1038/sj.gt.3302715

Middleton, P. G., Mall, M. A., Dřevínek, P., Lands, L. C., McKone, E. F., Polineni, D., et al. (2019). Elexacaftor-Tezacaftor-Ivacaftor for Cystic Fibrosis with a Single Phe508del Allele. N. Engl. J. Med. 381 (19), 1809-1819. doi:10.1056/ NEJMoa1908639

Milone, M. C., and O'Doherty, U. (2018). Clinical use of lentiviral vectors. Leukemia 32 (7), 1529-1541. doi:10.1038/s41375-018-0106-0

Modlich, U., and Baum, C. (2009). Preventing and exploiting the oncogenic potential of integrating gene vectors. J. Clin. Invest. 119 (4), 755-758. doi:10.1172/jci38831

Moss, R. B., Milla, C., Colombo, J., Accurso, F., Zeitlin, P. L., Clancy, J. P., et al. (2007). Repeated aerosolized AAV-CFTR for treatment of cystic fibrosis: a randomized placebo-controlled phase 2B trial. Hum. Gene Ther. 18 (8), 726-732. doi:10.1089/hum.2007.022
Moss, R. B., Rodman, D., Spencer, L. T., Aitken, M. L., Zeitlin, P. L., Waltz, D., et al. (2004). Repeated adeno-associated virus serotype 2 aerosol-mediated cystic fibrosis transmembrane regulator gene transfer to the lungs of patients with cystic fibrosis. Chest 125 (2), 509-521. doi:10.1378/chest.125.2.509

Naldini, L., Blomer, U., Gallay, P., Ory, D., Mulligan, R., Gage, F. H., et al. (1996). In vivo gene delivery and stable transduction of nondividing cells by a lentiviral vector. Science 272 (5259), 263-267. doi:10.1126/science.272.5259.263

Nathwani, A. C., Tuddenham, E. G. D., Rangarajan, S., Rosales, C., McIntosh, J., Linch, D. C., et al. (2011). Adenovirus-associated virus vector-mediated gene transfer in hemophilia B. N. Engl. J. Med. 365 (25), 2357-2365. doi:10.1056/ NEJMoa1108046

Nayak, S., and Herzog, R. W. (2010). Progress and prospects: immune responses to viral vectors. Gene Ther. 17 (3), 295-304. doi:10.1038/gt.2009.148

Noone, P. G., Hohneker, K. W., Zhou, Z., Johnson, L. G., Foy, C., Gipson, C., et al. (2000). Safety and biological efficacy of a lipid-CFTR complex for gene transfer in the nasal epithelium of adult patients with cystic fibrosis. Mol. Ther. 1 (1), 105-114. doi:10.1006/mthe.1999.0009

Oakland, M., Maury, W., McCray, P. B., Jr., and Sinn, P. L. (2013). Intrapulmonary versus nasal transduction of murine airways with GP64-pseudotyped viral vectors. Mol. Ther. Nucleic Acids 2, e69. doi:10.1038/mtna.2012.60

Palfi, S., Gurruchaga, J. M., Ralph, G. S., Lepetit, H., Lavisse, S., Buttery, P. C., et al. (2014). Long-term safety and tolerability of ProSavin, a lentiviral vector-based gene therapy for Parkinson's disease: a dose escalation, open-label, phase 1/2 trial. The Lancet 383 (9923), 1138-1146. doi:10.1016/S0140-6736(13)61939-X

Palmer, D. J., Turner, D. L., and Ng, P. (2020). A single “All-in-One" helperdependent adenovirus to deliver donor DNA and CRISPR/Cas9 for efficient homology-directed repair. Mol. Ther. Methods Clin. Dev. 17, 441-447. doi:10. 1016/j.omtm.2020.01.014

Parks, R. J., Chen, L., Anton, M., Sankar, U., Rudnicki, M. A., and Graham, F. L. (1996). A helper-dependent adenovirus vector system: removal of helper virus by Cre-mediated excision of the viral packaging signal. Proc. Natl. Acad. Sci. 93 (24), 13565-13570. doi:10.1073/pnas.93.24.13565

Persons, D. A. (2010). Targeting $\beta$-thalassaemia. Nature 467 (7313), 277-278. doi:10.1038/467277a

Pickles, R. J., McCarty, D., Matsui, H., Hart, P. J., Randell, S. H., and Boucher, R. C. (1998). Limited entry of adenovirus vectors into well-differentiated airway epithelium is responsible for inefficient gene transfer. J. Virol. 72 (7), 6014-6023. doi:10.1128/JVI.72.7.6014-6023.1998

Pilewski, J. M., Engelhardt, J. F., Bavaria, J. E., Kaiser, L. R., Wilson, J. M., and Albelda, S. M. (1995). Adenovirus-mediated gene transfer to human bronchial submucosal glands using xenografts. Am. J. Physiol.-Lung Cell. Mol. Physiol. 268 (4 Pt 1), L657-L665. doi:10.1152/ajplung.1995.268.4.L657

Porteous, D., Dorin, J., McLachlan, G., Davidson-Smith, H., Davidson, H., Stevenson, B., et al. (1997). Evidence for safety and efficacy of DOTAP cationic liposome mediated CFTR gene transfer to the nasal epithelium of patients with cystic fibrosis. Gene Ther. 4 (3), 210-218. doi:10.1038/sj.gt. 3300390

Ramsey, B. W., Davies, J., McElvaney, N. G., Tullis, E., Bell, S. C., Dřevínek, P., et al. (2011). A CFTR potentiator in patients with cystic fibrosis and theG551DMutation. N. Engl. J. Med. 365 (18), 1663-1672. doi:10.1056/ NEJMoa1105185

Resnier, P., Mottais, A., Sibiril, Y., Le Gall, T., and Montier, T. (2016). Challenges and successes using nanomedicines for aerosol delivery to the airways. Cgt 16 (1), 34-46. doi:10.2174/1566523216666160104142013

Rich, D. P., Anderson, M. P., Gregory, R. J., Cheng, S. H., Paul, S., Jefferson, D. M., et al. (1990). Expression of cystic fibrosis transmembrane conductance regulator corrects defective chloride channel regulation in cystic fibrosis airway epithelial cells. Nature 347 (6291), 358-363. doi:10.1038/347358a0

Riordan, J. R., Rommens, J., Kerem, B., Alon, N., Rozmahel, R., Grzelczak, Z., et al. (1989). Identification of the cystic fibrosis gene: cloning and characterization of complementary DNA. Science 245 (4922), 1066-1073. doi:10.1126/science. 2475911

Rivadeneira, E. D., Popescu, N. C., Zimonjic, D. B., Cheng, G. S., Nelson, P. J., Ross, M. D., et al. (1998). Sites of recombinant adeno-associated virus integration. Int. J. Oncol. 12 (4), 805-810. doi:10.3892/ijo.12.4.805

Rommens, J., Iannuzzi, M., Kerem, B., Drumm, M., Melmer, G., Dean, M., et al. (1989). Identification of the cystic fibrosis gene: chromosome walking and jumping. Science 245 (4922), 1059-1065. doi:10.1126/science.2772657 
Rowe, S. M., Daines, C., Ringshausen, F. C., Kerem, E., Wilson, J., Tullis, E., et al. (2017). Tezacaftor-ivacaftor in residual-function heterozygotes with cystic fibrosis. N. Engl. J. Med. 377 (21), 2024-2035. doi:10.1056/ NEJMoa 1709847

Ruiz, F. E., Clancy, J. P., Perricone, M. A., Bebok, Z., Hong, J. S., Cheng, S. H., et al. (2001). A clinical inflammatory syndrome attributable to aerosolized lipidDNA administration in cystic fibrosis. Hum. Gene Ther. 12 (7), 751-761. doi:10. 1089/104303401750148667

Samulski, R. J., Zhu, X., Xiao, X., Brook, J. D., Housman, D. E., Epstein, N., et al. (1991). Targeted integration of adeno-associated virus (AAV) into human chromosome 19. EMBO J. 10 (12), 3941-3950. doi:10.1002/j.1460-2075.1991. tb04964.x

Schneider-Futschik, E. K. (2019). Beyond cystic fibrosis transmembrane conductance regulator therapy: a perspective on gene therapy and small molecule treatment for cystic fibrosis. Gene Ther. 26 (9), 354-362. doi:10. 1038/s41434-019-0092-5

Schuster, B. S., Kim, A. J., Kays, J. C., Kanzawa, M. M., Guggino, W. B., Boyle, M. P., et al. (2014). Overcoming the cystic fibrosis sputum barrier to leading adenoassociated virus gene therapy vectors. Mol. Ther. 22 (8), 1484-1493. doi:10. 1038/mt.2014.89

Sinn, P. L., Arias, A. C., Brogden, K. A., and McCray, P. B., Jr. (2008). Lentivirus vector can be readministered to nasal epithelia without blocking immune responses. Jvi 82 (21), 10684-10692. doi:10.1128/JVI.00227-08

Sinn, P. L., Penisten, A. K., Burnight, E. R., Hickey, M. A., Williams, G., McCoy, D. M., et al. (2005). Gene transfer to respiratory epithelia with lentivirus pseudotyped with Jaagsiekte sheep retrovirus envelope glycoprotein. Hum. Gene Ther. 16 (4), 479-488. doi:10.1089/hum.2005.16.479

Steines, B., Dickey, D. D., Bergen, J., Excoffon, K. J. D. A., Weinstein, J. R., Li, X., et al. (2016). CFTR gene transfer with AAV improves early cystic fibrosis pig phenotypes. JCI Insight 1 (14), e88728. doi:10.1172/jci.insight.88728

Stern, M., Ulrich, K., Geddes, D. M., and Alton, E. W. F. W. (2003). Poly (D, L-lactide-co-glycolide)/DNA microspheres to facilitate prolonged transgene expression in airway epithelium in vitro, ex vivo and in vivo. Gene Ther. 10 (16), 1282-1288. doi:10.1038/sj.gt.3301994

Taylor-Cousar, J. L., Munck, A., McKone, E. F., van der Ent, C. K., Moeller, A., Simard, C., et al. (2017). Tezacaftor-ivacaftor in patients with cystic fibrosis homozygous for Phe508del. N. Engl. J. Med. 377 (21), 2013-2023. doi:10.1056/ NEJMoa1709846

Wagner, J. A., Messner, A. H., Moran, M. L., Daifuku, R., Kouyama, K., Desch, J. K., et al. (1999). Safety and biological efficacy of an adeno-associated virus vectorcystic fibrosis transmembrane regulator (AAV-CFTR) in the cystic fibrosis maxillary sinus. Laryngoscope 109 (2 Pt 1), 266-274. doi:10.1097/00005537199902000-00017

Wagner, J. A., Moran, M. L., Messner, A. H., Daifuku, R., Conrad, C. K., Reynolds, T., et al. (1998). A phase I/II study of tgAAV-CF for the treatment of chronic sinusitis in patients with cystic fibrosis. Stanford University, Stanford, California. Hum. Gene Ther. 9 (6), 889-909. doi:10. 1089/hum.1998.9.6-889

Wagner, J. A., Nepomuceno, I. B., Messner, A. H., Moran, M. L., Batson, E. P., Dimiceli, S., et al. (2002). A phase II, double-blind, randomized, placebocontrolled clinical trial of tgAAVCF using maxillary sinus delivery in patients with cystic fibrosis with antrostomies. Hum. Gene Ther. 13 (11), 1349-1359. doi:10.1089/104303402760128577

Wainwright, C. E., Elborn, J. S., Ramsey, B. W., Marigowda, G., Huang, X., Cipolli, M., et al. (2015). Lumacaftor-Ivacaftor in patients with cystic fibrosis homozygous for Phe508del CFTR. N. Engl. J. Med. 373 (3), 220-231. doi:10. 1056/NEJMoa1409547

Wickham, T. J., Mathias, P., Cheresh, D. A., and Nemerow, G. R. (1993). Integrins $\operatorname{av} \beta 3$ and $\alpha v \beta 5$ promote adenovirus internalization but not virus attachment. Cell 73 (2), 309-319. doi:10.1016/0092-8674(93)90231-e

$\mathrm{Wu}, \mathrm{Z}$., Yang, H., and Colosi, P. (2010). Effect of genome size on AAV vector packaging. Mol. Ther. 18 (1), 80-86. doi:10.1038/mt.2009.255

Xia, E., Munegowda, M. A., Cao, H., and Hu, J. (2014). Lung gene therapy-How to capture illumination from the light already present in the tunnel. Genes Dis. 1 (1), 40-52. doi:10.1016/j.gendis.2014.06.001

Yan, Z., Lei-Butters, D. C. M., Keiser, N. W., and Engelhardt, J. F. (2013). Distinct transduction difference between adeno-associated virus type 1 and type 6 vectors in human polarized airway epithelia. Gene Ther. 20 (3), 328-337. doi:10.1038/gt.2012.46

Yan, Z., McCray Jr, P. B., Jr., and Engelhardt, J. F. (2019). Advances in gene therapy for cystic fibrosis lung disease. Hum. Mol. Genet. 28 (R1), R88-R94. doi:10. 1093/hmg/ddz139

Yan, Z., Stewart, Z. A., Sinn, P. L., Olsen, J. C., Hu, J., McCray, P. B., Jr., et al. (2015). Ferret and pig models of cystic fibrosis: prospects and promise for gene therapy. Hum. Gene Ther. Clin. Dev. 26 (1), 38-49. doi:10.1089/humc.2014.154

Ylä-Herttuala, S. (2012). Endgame: glybera finally recommended for approval as the first gene therapy drug in the European Union. Mol. Ther. 20 (10), 1831-1832. doi:10.1038/mt.2012.194

Yonemitsu, Y., Kitson, C., Ferrari, S., Farley, R., Griesenbach, U., Judd, D., et al. (2000). Efficient gene transfer to airway epithelium using recombinant Sendai virus. Nat. Biotechnol. 18 (9), 970-973. doi:10.1038/79463

Yu-Wai-Man, P., Newman, N. J., Carelli, V., Moster, M. L., Biousse, V., Sadun, A. A., et al. (2020). Bilateral visual improvement with unilateral gene therapy injection for Leber hereditary optic neuropathy. Sci. Transl. Med. 12 (573), eaaz7423. doi:10.1126/scitranslmed.aaz7423

Zabner, J., Cheng, S. H., Meeker, D., Launspach, J., Balfour, R., Perricone, M. A., et al. (1997). Comparison of DNA-lipid complexes and DNA alone for gene transfer to cystic fibrosis airway epithelia in vivo. J. Clin. Invest. 100 (6), 1529-1537. doi:10.1172/JCI119676

Zabner, J., Couture, L. A., Gregory, R. J., Graham, S. M., Smith, A. E., and Welsh, M. J. (1993). Adenovirus-mediated gene transfer transiently corrects the chloride transport defect in nasal epithelia of patients with cystic fibrosis. Cell 75 (2), 207-216. doi:10.1016/0092-8674(93)80063-k

Zabner, J., Ramsey, B. W., Meeker, D. P., Aitken, M. L., Balfour, R. P., Gibson, R. L., et al. (1996). Repeat administration of an adenovirus vector encoding cystic fibrosis transmembrane conductance regulator to the nasal epithelium of patients with cystic fibrosis. J. Clin. Invest. 97 (6), 1504-1511. doi:10.1172/ JCI118573

Conflict of Interest: The authors declare that the research was conducted in the absence of any commercial or financial relationships that could be construed as a potential conflict of interest.

Copyright $\odot 2021$ Mercier, Ruffin, Corvol and Guillot. This is an open-access article distributed under the terms of the Creative Commons Attribution License (CC BY). The use, distribution or reproduction in other forums is permitted, provided the original author(s) and the copyright owner(s) are credited and that the original publication in this journal is cited, in accordance with accepted academic practice. No use, distribution or reproduction is permitted which does not comply with these terms. 